\title{
FORMAÇÃO DOCENTE EM TEATRO: PESQUISA ALIADA À AÇÃO PEDAGóGICA
}

\author{
Vera Lúcia Bertoni dos Santos ${ }^{1}$
}

Este trabalho resulta da etapa preliminar de uma pesquisa mais ampla que se relaciona intimamente à trajetória acadêmica da sua autora junto à formação docente em teatro e delineia-se em seguimento a investigações anteriores, através das quais se tem buscado refletir sobre o processo de formação do professor de teatro sob a ótica interacionista. Nele apresentam-se alguns resultados dessa pesquisa mais atual e anunciam-se possibilidades de continuidade e aprofundamento das reflexões oportunizadas pela prática pedagógica impulsionada, ou desafiada, pela curiosidade científica.

A base empírica da parte da pesquisa da qual se extraem os resultados a serem apresentados constituiu-se a partir do processo cooperativo de elaboração, execução e avaliação de um Laboratório de Prática Docente, desenvolvido por estudantes do Curso de Licenciatura em Teatro do Departamento de Arte Dramática (DAD) da Universidade Federal do Rio Grande do Sul, sob orientação da coordenadora da pesquisa, e oferecido a um grupo de jovens da comunidade.

Dessa experiência pedagógica refletida emergiram questões e problemas identificados a interesses individuais das estudantes de graduação, que, assumidos como ideais de pesquisa, foram analisados e compreendidos num contexto mais amplo e relacionados a um quadro conceitual que lhes permitiu identificar a problemática mais ampla a que se vinculavam e definir métodos adequados à sua investigação.

A articulação dessas "sub-pesquisas" entre si precipitou uma "metapesquisa" que busca compreender a complexidade do processo de conhecimento dos sujeitos da relação educativa por meio da interpretação das suas formulações teóricas e da observação da sua ação pedagógica.

${ }^{1}$ Doutora em Educação pela UFRGS; Professora e pesquisadora do Departamento de Arte Dramática e do Programa de PósGraduação em Artes Cênicas da UFRGS; Coordenadora da Pesquisa Professor e Teatro e Construção de Conhecimento: 0 Laboratório de Prática Docente, com registro no Sistema de Pesquisa da UFRGS e apoio PROPESQ/UFRGS e FAPERGS; Líder do GESTE - Grupo de Estudos em Teatro e Educação (CNPq); autora de diversas obras envolvendo as relações entre teatro e educação; atriz de teatro. 


\section{Urdimento}

${ }^{2}$ Tais resultados referem-se ao trabalho investigativo e reflexivo realizado no decorrer do ano de 2007, que contou com a inestimável colaboração das acadêmicas da UFRGS, Adriana Serrão Schneider, Daniela Dutra Silveira, Luciana Rodrigues Marcon e Marcia Kopczynski de Freitas Filha, Bolsistas de Iniciação Científica da Pesquisa.

${ }^{3}$ Componente curricular obrigatório do Curso de Licenciatura em Teatro da UFRGS, que prevê o desenvolvimento de uma situação real de docência coletiva e reflexiva acerca da ação pedagógica em teatro.
O objetivo primordial dessa meta-pesquisa é ampliar o debate sobre a construção de conhecimento em teatro sob a ótica interacionista de Jean Piaget, a perspectiva dialógica de Paulo Freire e a pedagogia teatral de Viola Spolin e Jean-Pierre Ryngaert, dentre outros autores que problematizam a construção de conhecimento em teatro na contemporaneidade.

Longe da intenção de estabelecer princípios norteadores à ação docente no ensino superior ou de traçar uma metodologia precisa de pesquisa aliada à docência, neste recorte pretende-se identificar evidências de uma pedagogia comprometida com a transformação do conhecimento, com vistas a compartilhar uma visão particular do processo interativo, construtivo, relacional e permanente que envolve a formação docente em teatro na UFRGS.

\section{Dos problemas e dos propósitos}

A pesquisa da qual se extraem os resultados parciais ${ }^{2}$ que aqui se expõem intitula-se Professor de Teatro e Construção de Conhecimento: o Laboratório de Prática Docente e delineia-se em continuidade à investigação que originou a Tese de Doutorado da sua autora, denominada No fio do equilibrista: professor de teatro e construção de conhecimento, ambas motivadas pelo trabalho docente e reflexivo que realiza na interação com estudantes do Curso de Licenciatura em Teatro da UFRGS.

O propósito central da investigação mais ampla é aprofundar a discussão sobre a (trans)formação do professor de teatro e as suas relações com a construção da inteligência (compreendida, esta, como forma complexa de adaptação do ser humano ao mundo em que vive), e explorar diversas facetas desse processo. Ou seja, a problemática mais abrangente da pesquisa compreende o processo de formação do professor de teatro, situando-se na intersecção das áreas do teatro e da educação.

Subordinada a esse objetivo geral, a etapa a qual se referem os resultados a serem apresentados compreende, em especial, os processos de ensino e aprendizagem desenvolvidos por um grupo de quatro licenciandas em teatro que, tendo cursado, com destaque, a disciplina de Metodologia do Ensino do Teatro ${ }^{3}$, aceitou o convite da coordenadora (professora da disciplina e coordenadora da pesquisa) para dar continuidade às reflexões e interações propiciadas naquela ocasião, mediante a participação numa experiência coletiva de Laboratório de Prática Docente.

Dentre os objetivos mais específicos do trabalho investigativo ligado à experiência em questão, destacam-se: a reflexão acerca do significado do trabalho docente através da análise da prática teatral; a tematização das relações 


\section{Urdimento}

entre teoria e experimentação; a compreensão da intencionalidade das ações pedagógicas, tais como, a intervenção nas relações interpessoais, a seleção e a abordagem dos conteúdos, a avaliação e a cooperação; a problematização do papel do teatro na sua relação com a educação, com ênfase na busca de reconhecimento da importância do "processo" em relação ao "produto" (tradicionalmente valorizado no meio escolar), mas sem detrimento do produto (na medida em que ele se constitua por interesse do grupo e criação coletiva); a reflexão sobre diferentes aspectos do processo de construção (apropriação) de elementos fundamentais do teatro (representação perante platéia com o intuito de comunicar), tendo em vista os modelos tradicionais de teatro e de representação que significam identificação e mostram-se através do gesto (corpos/vozes, intenções e ações) dos aprendizes; a análise minuciosa do processo de transição entre a dramatização espontânea, característica das etapas mais desenvolvidas do simbolismo coletivo (Piaget, 1946), e a arte teatral contemporânea; a busca de substrato teórico acerca das modalidades de improvisação do jogo dramático (Ryngaert, 1977) e dos jogos teatrais (Spolin, 1963) e a compreensão dessas modalidades como vias de aprendizagem do teatro num projeto educacional contemporâneo; a sistematização de um repertório de proposições ou procedimentos para a abordagem pedagógica de elementos (espaço, corpo/voz, estrutura da narrativa, diálogos) do conhecimento teatral; e a ampliação das possibilidades de intervenção pedagógica e de inserção do teatro no meio escolar.

Atenta à interação com tantos e tão complexos e multifacetados aspectos do processo de construção de conhecimento em teatro, o Laboratório de Prática Docente visava evidenciar os caracteres relacional e processual da ação pedagógica em teatro, considerados, na perspectiva interacionista, qualidades intrínsecas à formação reflexiva do professor de teatro.

Nesse sentido, salientaram-se alguns fatores cruciais concorrentes para o avanço das reflexões sobre a práxis ${ }^{4}$ na formação docente, tais como: a qualidade do envolvimento do grupo de licenciandas que se dispuseram a participar como Bolsistas de Iniciação Científica da pesquisa; o rigor científico que caracterizou os debates travados entre elas; a busca constante de interação entre teoria e experimentação, aspecto que contribui de maneira decisiva para o desenvolvimento da curiosidade científica dessas professoras em formação; e a compreensão do processo de conhecimento numa perspectiva dialética ${ }^{5}$, que permitiu enfatizar a unidade do processo de ensino e aprendizagem sob o ponto de vista da interação entre o pesquisador e os sujeitos que compartilham a situação empírica, entre o sujeito do conhecimento e seu objeto, e entre os fazeres teóricos e práticos relacionados à aprendizagem do teatro.
${ }^{4} \mathrm{Na}$ análise do diálogo que caracteriza os processos pedagógicos segundo a perspectiva de Freire (1987, p. 77), a palavra deve ser compreendida no seu sentido radical, ou seja, mais do que um meio para que 0 diálogo se produza, a palavra merece ser analisada como "práxis", termo que comporta as suas duas dimensões constitutivas: ação e reflexão.

${ }^{5} \mathrm{Na}$ filosofia moderna e contemporânea 0 termo é freqüentemente utilizado no sentido de Hegel. "Toda a realidade move-se dialeticamente e, portanto, a filosofia hegeliana vê em toda parte tríades de teses, antíteses e sínteses, nas quais a antítese representa a 'negação', o 'oposto' ou 'outro' da tese, e a síntese constitui unidade e, ao mesmo tempo, a certificação de ambas" (Abbagnano, 1998, p. 273). 


\section{Do campo, dos sujeitos e da metodologia}

A base empírica do trabalho investigativo estruturou-se a partir da seleção e preparo da equipe da pesquisa, que envolveu cinco bolsistas de Iniciação Científica (três Bolsistas PROPESQ/UFRGS e uma Bolsista FAPERGS), todas estudantes de graduação do Curso de Licenciatura em Teatro, que se destacaram pela qualidade da sua participação, empenho e iniciativa nas atividades realizadas na disciplina de Metodologia do Ensino do Teatro.

Essa estruturação permitiu o desenvolvimento do processo de elaboração, execução e avaliação de um Laboratório de Prática Docente ocorrido nas dependências do Departamento de Arte Dramática da UFRGS e oferecido a um grupo de alunos da comunidade. E a preparação da equipe de bolsistas para o trabalho pedagógico deu-se a partir de seminários sobre textos teóricos, exposições e debates que versavam sobre diferentes aspectos do processo de conhecimento em teatro, abarcando caracteres estéticos, artísticos e pedagógicos do fazer teatral.

O Laboratório, denominado pelas bolsistas de Oficina de Teatro para Iniciantes, desdobrou-se em dois módulos, que ocorreram, o primeiro, entre os meses de maio a junho, e, o segundo, entre os meses de agosto e outubro de 2007, totalizando quatorze encontros (de duas horas semanais) e congregando um contingente de vinte e três alunos (jovens com idades entre onze e dezoito anos).

A análise da experiência docente propiciada pela interação com o grupo de jovens seguiu diversas linhas investigativas, tais como: a reflexão sobre a formação do professor de teatro; a problematização das trajetórias pessoais das professoras pesquisadoras, relacionadas ao teatro e à educação; a observação participante e a avaliação constante do desenvolvimento do processo de conhecimento do grupo de jovens com o qual elas compartilharam a sala de aula; e a teorização sobre o desenrolar dos processos de aprendizagem evidenciados no decorrer do trabalho.

A reflexão sobre os acontecimentos da sala de aula e a elaboração da teoria que a sustenta e desafia relacionam-se intimamente à postura do "professor pesquisador”, compreendida segundo a perspectiva de Freire. Nessa concepção:

O que há de pesquisador no professor não é uma qualidade ou uma forma de ser ou de atuar que se acrescente à de ensinar. Faz parte da natureza da prática docente a indagação, a busca, a pesquisa. O de que se precisa é que, em sua formação permanente, o professor se perceba e se assuma, porque professor, pesquisador. (Freire, 1996, p. 32) 
Para Freire, a assunção dessa postura não ocorre de forma automática ou pré-determinada, pois emana do compromisso permanente do professor com o desenvolvimento da sua consciência crítica, vinculada, por sua vez, às crescentes capacidades de indagação e busca que lhe possibilitam transformar a chamada “curiosidade ingênua” em “curiosidade epistemológica” (Freire, 1996, p. 32).

Na concepção de Piaget (1974a e 1974b) essa transformação depende do mecanismo de tomada de consciência, relacionado ao processo de conceituação, ou seja, à "passagem da assimilação prática a uma assimilação por meio de conceitos”, e correspondente, no seu quadro teórico, à idéia de "aprendizagem no sentido amplo", que se vincula estreitamente ao processo dinâmico de equilibração das estruturas de conhecimento, implicado, por sua vez, à criação da "novidade".

No sentido do delineamento teórico da pesquisa, autores como Ryngaert, Spolin(1963), Ingrid Koudela e Maria Lúcia Pupo entre outros, fornecem elementos para refletir sobre a complexidade do processo de construção da teatralidade.

Concorrem também aspectos do método clínico ligado à Epistemologia Genética, refletidos através da leitura da obra de Piaget e seus colaboradores, em especial os estudos voltados à compreensão dos processos de aprendizagem e conhecimento.

Tendo por base teórica esses referenciais realiza-se um estudo descritivo, analítico e reflexivo das (trans)formações dos sujeitos do processo de formação docente, compreendidas numa totalidade coordenada, na qual se busca equilibrar o estudo da teoria e a análise da prática, alicerces e reflexos uma da outra.

Um dos princípios que orienta a investigação é que o professor de teatro é um pesquisador envolvido com a produção e difusão do conhecimento teatral e que não pode ser considerado um profissional de segunda classe que não precisa ir tão fundo nos conhecimentos específicos da área do teatro. Ou seja, é um profissional em construção de domínios fundamentais à expressão e compreensão de visões de mundo através da materialidade de uma determinada forma artística - o teatro -, e em desenvolvimento da sua capacidade de transpor essa materialidade às necessidades de aprendizagem dos seus alunos, significando novas possibilidades de reflexão sobre o mundo.

A análise do material coletado possibilitou reconstruir, explorar e ampliar a compreensão das ações empreendidas no sentido da transformação dos conhecimentos como necessidade dos sujeitos envolvidos nesse processo construtivo, gerando novos percursos cada vez mais adaptados às necessidades de conhecimento evidenciadas nesse contexto. 


\section{Dos resultados e dos desdobramentos}

Da teorização dessa experiência emergiram questões identificadas a interesses individuais das licenciandas, dentre as quais se evidenciam: a busca de compreensão da sala de aula como espaço-tempo de compartilhamento da experiência estética e ética em teatro; a compreensão do papel da tomada de consciência na formação do professor de teatro; a investigação acerca das relações entre a teoria e prática e entre ação e reflexão no processo de conhecimento relacionado à expressão vocal na iniciação teatral; e o estudo do processo de interação professor-aluno e suas relações com o ensino-aprendizagem do teatro.

Essas questões foram assumidas como ideais de pesquisa das estudantes, professoras-pesquisadoras em formação, sendo analisadas e compreendidas num contexto mais amplo e relacionadas a um quadro conceitual que permitiu a cada uma delas identificar a problemática a que se vinculam, estabelecer metodologias adequadas à sua elucidação e "dar corpo" às suas próprias idéias, mediante categorizações e análises coerentes e consistentes.

No trabalho intitulado Teatro como Encontro: uma experiência na sala de aula, a bolsista Adriana Serrão Schneider analisou a relação entre "quem está em cena e quem está na platéia”, salientando a importância da comunicação no ato teatral e questionando as funções de ator e de espectador, exercitadas pelos alunos nos trabalhos cênicos de sala de aula.

Para refletir sobre essas questões ela partiu da análise de experiências teatrais que a transformaram como espectadora e como aluna-atriz e investigou a possibilidade de desenvolver experiências éticas e estéticas com os alunos do Laboratório.

Suas reflexões fundamentaram-se em princípios lúdicos e experiências teatrais desenvolvidas em sala de aula e registradas através de escritos e imagens (fotos e filmagens), envolvendo a sistematização de referenciais teóricos e de impressões e avaliações do grupo sobre o trabalho realizado. $\mathrm{Na}$ análise dos exercícios e improvisações teatrais, em acordo com teóricos como Peter Brook e Paulo Freire, dentre outros, a professora em formação observou o alargamento dos referenciais dos alunos, tanto no que diz respeito à qualidade de "estar em cena", quanto à de "ser platéia".

Nesse sentido, ela passou a entender a criação teatral como "possibilidade de troca, de transformação das relações e de ampliação das visões de mundo”, ou seja, passou a analisar o fenômeno teatral como "encontro entre seres humanos que se aprendem mutuamente, que se enriquecem uns aos outros com suas experiências". 
A bolsista Daniela Dutra Silveira, autora de O Valor da Memória na Formação Docente, realizou um estudo sobre o papel da tomada de consciência na trajetória dos próprios integrantes da pesquisa, ou seja, os professorespesquisadores, tendo por base empírica o Memorial, instrumento de coleta dos dados que constituiu oportunidade de descrição e reflexão das histórias de vida dos professores em formação.

No Memorial, as integrantes da pesquisa foram desafiadas a pensar sobre suas experiências mais significativas em relação ao teatro e à educação, resultando uma produção textual que foi analisada com o propósito de entender como é que ocorre a tomada de consciência dos processos de construção de conhecimento.

A base teórica das reflexões sobre esses processos constituiu-se por princípios de autores, tais como, Piaget, Freire, Spolin e Ryngaert, cuja leitura auxiliou a professora-pesquisadora a compreender os processos de conhecimento em teatro.

Luciana Rodrigues Marcon, cujo trabalho intitulou-se Cantando na Chuva: para uma pedagogia vocal no teatro, partiu da sua própria trajetória como atriz, cantora e orientadora vocal na preparação de atores e investigou as relações entre a formação do professor de teatro e a sua prática docente, tendo por objetivo central problematizar os procedimentos do professor de teatro ao propiciar um ambiente onde possam se desenvolver habilidades vocais que fazem parte do aprendizado da iniciação teatral.

Partindo da idéia de que o trabalho coletivo com a voz evidencia a necessidade de exposição individual e, por conseguinte, o relacionamento de grupo, ela enfocou o papel da espontaneidade como fator de desenvolvimento do trabalho vocal no processo de iniciação teatral.

Finalmente, no trabalho intitulado Professor e aluno construindo identidades na prática teatral, a bolsista Marcia Kopczynski de Freitas Filha pesquisou a relação que se estabelece entre os professores-pesquisadores e os alunos no Laboratório de Prática Docente, com vistas à ampliação do processo de ensino-aprendizagem de teatro.

Tendo por base empírica o planejamento, a execução e a avaliação das atividades em jogo no Laboratório, ela partiu da hipótese que o processo de formação docente relaciona-se ao tipo de relação que o professor estabelece com os alunos e às escolhas das propostas pedagógicas, das condutas e das abordagens das situações de sala de aula. 
Como aspectos analisados no seu trabalho, destacam-se: a construção da identidade docente, que se dá, dentre outros fatores, através da relação estabelecida entre professor e aluno; o espaço pedagógico como possibilidade de construção de uma relação na qual os participantes (professor e alunos) constituem-se pelo compartilhamento do conhecimento; e o princípio de que quem ensina, aprende ao ensinar, e vice-versa, através do trabalho coletivo, da aceitação do outro e da reflexão teórica, indissociável na prática.

Os aspectos relativos a essas investigações (sub-pesquisas) individuais foram descritos em conjunto no Relatório apresentado no final de 2007, elaborado pela Bolsista BIC/PROPESQ/UFRGS, Adriana Serrão Schneider, e aprofundados individualmente nos Trabalhos de Conclusão do Curso de Licenciatura em Teatro das bolsistas, constituindo ricas oportunidades de discussão das questões levantadas pelos estudantes em particular.

A articulação dessas pesquisas entre si exigiu o desdobramento da pesquisa numa segunda etapa, que constitui uma espécie de "meta-pesquisa" dedicada à análise da complexidade do processo de conhecimento dos futuros professores de teatro por meio da interpretação das suas construções teóricas e da sua ação pedagógica, à luz da teoria.

\section{Referências Bibliográficas}

ABBAGNANO, Nicola. Dicionário de filosofia. São Paulo: Martins Fontes, 1998. FREIRE, Paulo. Pedagogia da autonomia: saberes necessários à prática educativa. São Paulo: Paz e Terra, 1997.

Pedagogia do Oprimido. Rio de Janeiro: Paz e Terra, 1987.

PIAGET, Jean. [1946] A formação do símbolo na criança. Rio de Janeiro: Zahar, 1978.

[1974a] A tomada de consciência. São Paulo: Melhoramentos, Ed. Da Universidade de São Paulo, 1977.

[1974b] Fazer e compreender. São Paulo: Melhoramentos, Ed. Da Universidade de São Paulo, 1978.

RYNGAERT, Jean Pierre. [1977] Ojogo dramático no meio escolar. Coimbra: Centelha, 1981.

SANTOS, Vera Lúcia Bertoni dos. No fio do equilibrista: professor de teatro e construção de conhecimento. Porto Alegre: PPGEdu/UFRGS, 2006. (Tese de Doutorado).

SPOLIN, Viola. [1963] Improvisação para o teatro. São Paulo: Perspectiva, 1979. 